\title{
Gayatri Mantra Chanting and its Effect on Attention, Memory, Anxiety and Mental State in Young Athletes: A Prospective Study
}

\author{
Shambo Samrat Samajdarl, Shatavisa Mukherjee ${ }^{1,}$ Anushka Ghosh ${ }^{1}$, Shashank Joshi², \\ Santanu Kumar Tripathi ${ }^{1}$
}

1. Department of Clinical and Experimental Pharmacology, School of Tropical Medicine, Kolkata, India.

2. Senior Consultant - Joshi Clinic, Lilavati Hospital, and Research Centre, Mumbai, India.

\begin{abstract}
Introduction: The Gayatri Mantra (GM) is one of the oldest available divine hymns in ancient Vedic literature, a mantra of physical, emotional, mental healing, and spiritual awakening or self-realization. GM is a standard, validated, empowerment tool aiding in effective behavioral changes leading to an optimal and healthy lifestyle. The effect of Vedic chanting on consciousness and mental state has been long researched. It has been documented in ancient religious literature. However, due to its religious connotations, its scientific scrutiny and validation have not been popularized. The present study tried to assess the effect of GM chanting on attention, memory, anxiety, and mental state on healthy young athletes. Methodology: The present study was a prospective one, which included 45 athletes who were divided into three different study arms of 15 each - two arms were undertaking meditation with or without an add on GM Chanting while meditation, while one was a control group. All subjects were evaluated at baseline and three months for attention (using six-letter cancellation, digit letter substitution), memory [using digit span test (forward, backward), multiple-choice apparatus], anxiety (using state-trait anxiety inventory), and mental state using MMSE. The results were statistically analyzed. Results: Subjects with GM chanting showed significant improvement in attention and memory domain. Less failed attempts and prompt response to audio and visual stimuli for multiple-choice apparatus was noted for the GM group. Sustained visual attention, scanning without distraction, and better concentration are required for the digit cancellation test. Marked improvements in both state and trait anxiety were noted for the GM chanters. The improved mental state was observed for both meditating groups compared with the control. Conclusion: $G M$ chanting plays a significant role in the well being of the people. GM chanting has significant effects on attention, memory, anxiety, and mental state. Regular chanting of GM shall improve learning power, concentration, prosperity, eternal power, peace, and improves the quality of life.
\end{abstract}

KEYWORDS: Gayatri Mantra; Six letter cancellation; digit letter substitution; state trait anxiety inventory; MMSE.

\section{INTRODUCTION}

$\mathrm{T}$ The Sanskrit word 'Mantra' is a paradox, which is the combination of two roots. One roots means repetition, the other means freedom. While repetition symbolizes discipline, freedom denotes empowerment. The word itself implies a definite structure of syllables and vowels, which work as an excellent spiritual tool to liberate the mind from ignorance, illusion and delusion. It ignites the potential to achieve state of "mindfulness" or "calm". Researchers have also postulated that yogic mantras and chants gives positive influence, vibration on physiological and psychological functions of the body.[1] The Gayatri Mantra(GM) is one of the oldest available divine hymns in ancient vedic literature which is more than 10,000 years old. Gayatri is a mantra of physical, emotional, mental healing and spiritual awakening or self-realization.GM is a

Correspondence: Shatavisa Mukherjee, Department of Clinical \& Experimental Pharmacology,

School of Tropical Medicine, Kolkata 700073, West Bengal, India. E-mail: shatavisa100@gmail.com

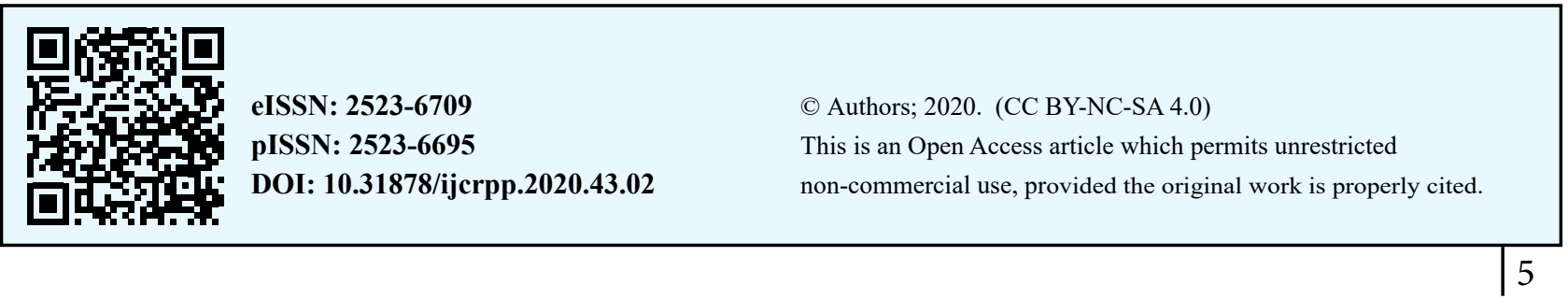


Table 1. Effect of GM Chanting on Attention, Memory, Anxiety parameters

\begin{tabular}{|c|c|c|c|c|}
\hline Parameters & Baseline & Group 1 & Group 2 & Group 3 \\
\hline \multicolumn{5}{|c|}{ Attention parameters } \\
\hline \multicolumn{5}{|l|}{ Digit Cancellation Test } \\
\hline Mean Digit Cancellation Score & $25.93 \pm 9.98$ & $41.87 \pm 9.23^{*}$ & $36.93 \pm 5.23^{*}$ & $25.53 \pm 7.62^{\mathrm{NS}}$ \\
\hline \multicolumn{5}{|l|}{ Digit Letter Substitution Test } \\
\hline Mean Digit LetterSubstitution Score & $41.67 \pm 10.61$ & $54.40 \pm 7.68^{*}$ & $51.07 \pm 4.63^{* *}$ & $41.73 \pm 9.76^{\mathrm{NS}}$ \\
\hline \multicolumn{5}{|c|}{ Memory Parameters } \\
\hline \multicolumn{5}{|l|}{ Digit Span Test } \\
\hline Mean Digit Span Forward & $4.20 \pm 1.86$ & $6.02+1.55^{* * *}$ & $5.02 \pm 1.31^{\mathrm{NS}}$ & $4.29 \pm 1.03^{\mathrm{NS}}$ \\
\hline Mean Digit Span Background & $3.47 \pm 1.51$ & $4.56 \pm 1.50^{*}$ & $4.01 \pm 1.72^{\mathrm{NS}}$ & $3.76 \pm 1.09^{\mathrm{NS}}$ \\
\hline \multicolumn{5}{|l|}{ Multiple Choice Apparatus } \\
\hline Mean delay in RT to Visual Stimuli & $1.38+0.69$ & $1.02 \pm 0.61^{\mathrm{NS}}$ & $1.0 \pm 0.56^{\mathrm{NS}}$ & $1.30 \pm 0.54^{\mathrm{NS}}$ \\
\hline Mean delay in RT to Sound Stimuli & $1.90 \pm 1.06$ & $1.59 \pm 0.77^{\mathrm{NS}}$ & $1.67 \pm 0.52^{\mathrm{NS}}$ & $1.89 \pm 1.10^{\mathrm{NS}}$ \\
\hline \multicolumn{5}{|l|}{ Failed attempts } \\
\hline $\begin{array}{l}\text { Mean failed attempts for sound } \\
\text { stimuli }\end{array}$ & $\mathrm{d} 3.13 \pm 2.53$ & $1.53 \pm 0.83^{*}$ & $1.67 \pm 0.90^{*}$ & $3.13 \pm 1.96^{\mathrm{NS}}$ \\
\hline $\begin{array}{l}\text { Mean failed attempts for visual } \\
\text { stimuli }\end{array}$ & $0.53 \pm 0.83$ & $0.40 \pm 0.63^{\mathrm{NS}}$ & $0.67 \pm 0.62^{\mathrm{NS}}$ & $0.73 \pm 0.59^{\mathrm{NS}}$ \\
\hline \multicolumn{5}{|c|}{\begin{tabular}{|c|} 
Anxiety Parameters \\
\end{tabular}} \\
\hline \multicolumn{5}{|l|}{ STAI Inventory } \\
\hline $\begin{array}{l}\text { Mean STAIY1 } \\
\text { (State Anxiety Score) }\end{array}$ & $47.80 \pm 6.15$ & \begin{tabular}{|l|l|}
61.67 \\
$2.22^{* * *}$
\end{tabular} & $\begin{array}{l}61.67 \\
2.22^{* * * *} \\
\end{array}$ & $46.87 \pm 3.31^{\mathrm{NS}}$ \\
\hline $\begin{array}{l}\text { Mean STAIY2 } \\
\text { (Trait Anxiety Score) }\end{array}$ & $47.47 \pm 8.08$ & $\begin{array}{l}59.27 \\
4.60^{* * *} \\
\end{array}$ & \begin{tabular}{|l|l|}
57.47 \\
$3.89^{* * * *}$ \\
\end{tabular} & $45.13 \pm 6.56^{\mathrm{Ns}}$ \\
\hline \multicolumn{5}{|l|}{ Mental State (MMSE) } \\
\hline Mean MMSE Score & $25.47 \pm 1.64$ & $\begin{array}{l}27.60 \\
1.05^{* * * *}\end{array}$ & $27.27 \pm 1.0$ & $25.53 \pm 1.18^{\mathrm{NS}}$ \\
\hline
\end{tabular}

standard, validated, empowerment tool aiding in effective behavioral changes leading to optimal and healthy lifestyle. Effect of vedic chanting on consciousness and mental state has been long researched and has been documented in ancient religious literatures.[2] However, due to its religious connotations, its scientific scrutiny and validation has been not popularized. The present study uses modern scientific approaches to probe this hypothesis. The present study was carried out to assess the effect of GM chanting on attention, memory, anxiety and mental state on healthy young athletes

\section{Materials and Methods}

$\mathrm{T}$ he present study was a prospective one which included 45 athletes by convenience sampling who were divided into three different study arms (15 each) -

Group 1: Those undertaking normal meditation (15 minutes) with an add on GM Chanting while meditation

Group 2: Those undertaking normal meditation (15 minutes) without chanting any mantra

Group 3: Control group (without any meditation)

All willing and consenting athletes were included for the study. Those already diagnosed with depression and anxiety, or any other disease which could impact the psychometric assessments was excluded. All subjects were evaluated (at baseline and 3 months) for attention (using 6 letter cancellation, digit letter substitution), memory (using digit span test (forward, backward), multiple choice apparatus), anxiety (using state trait anxiety inventory), and mental state using Mini Mental State Examination (MMSE) inventory. Results were statistically analyzed. A p value of less than 0.05 was considered statistically significant.

\section{Results}

The mean age of the subjects was $21.60 \pm 1.84$ 1 years. Subjects with GM chanting showed significant improvement in attention parameters, with increased responses in 6 letter cancellation and digit letter substitution. (Table 1).

Significant improvement in memory domain was noted with higher responses for digit span test compared to the other two arms. Less failed attempts and prompt response to audio and visual stimuli for multiple choice apparatus was noted for the GM group.

Marked improvements in both state and trait anxiety was noted for the GM chant group with lesser improvement for only meditation group. Improved mental state was observed for both meditating group compared with the control.

\section{Discussion}

$\mathrm{V}$ edic mantras have been a part of the Indian tradition since ages. The sacred GM, also called savitr mantra (since pertaining to sun) was initially explained by Vishwamitra maharishi in 
Rig Veda. Since time immemorial, such mantras have been a part and parcel of Indian lives. Gayatri mantra consist twenty four letters, with every letters providing subtle conscious energy field and magnetic field around our body. The super natural impact of gayatri mantra is in the physical life due to some specific syllables of mantra.[3] The mantra as a whole stimulates the subliminal power centers in the subtle body. Repeated pressures on tongue, lips, vocal cords, palate and connecting region in the brain generated by continuous recitation of the 24 syllables of GM creates a resonance in the nerve and nadis in the body. It creates the magnetic force or electromagnetic wave around the body that attracts the vital current of deity SUN. Since thought to have positive influences on intelligence, students were advised to chant these mantras before the formal studies. Present day researches has boosted these ancient theories confirming positive impact of these mantras on both physiological and psychological functioning of the body.[4] Vedic chanting are thought to enhance the attention and recallability. Chanting further increases blood supply to the brain areas which are concerned with the memory, thus increasing memory organizability. Studies have demonstrated medial frontal gyrus activation attributing to increased concentration and visuospatial attention during chanting of mantras. Activation of left lateral middle frontal gyrus, the right angular gyrus, and the right supramarginal gyrus has also been noted which contributes to visuospatial attention.[5]While there are several studies assessing interventions like asana, pranayama, forms of meditation etc, studies assessing impact of vedic chanting on memory and associated parameters are comparatively less. Hence, the present study was undertaken to provide further scientific evidence for beneficial effect of GM chanting on cognitive functions in young adults and adolescents. In the present study, we have observed significant improvement in the spatial and verbal memory scores followed by the chanting GM. This is in similarity with another study analyzing effect of GM chanting in school children. [6]

The present study showed that subjects with GM chanting showed significant improvement in attention parameters, with increased responses in 6 letter cancellation and digit letter substitution. Results were observed to be similar with a study conducted in Maharashtra. [7] Significant improvement in memory domain was noted with higher responses for digit span test compared to the other two arms. Less failed attempts and prompt response to audio and visual stimuli was noted for the GM group. Sustained visual attention, scanning without distraction, and better concentration are required for the digit cancellation test. Better verbal and spatial scorings and decrease in total time taken; reduction in total errors could be related to the fact that reduced anxiety may have improved performance on tasks requiring learning and memory. Marked improvements in both state and trait anxiety was noted for the GM chant group with lesser improvement for only meditation group. Improved mental state was observed for both meditating group compared with the control. Decreased anxiety state and persistent calmness of mind combined with active cells due to rhythmic vedic mantra chanting could have attributed to improved memory, mental concentration and sustained attention.

However, our study had certain limitations. The study was of a short duration one and should involve larger sample size to generalize the result in future.GM chanting may be implemented in school setting to help raise the concentration of the students thus aiding in improved academic ability along with all round development. Future research may consider including different age groups of students with different levels of attention, assessment methods to check physiological changes. This can be repeated irrespective of any religions.

\section{Conclusion}

GM chanting plays a significant role in the well being of the people. GM chanting has significant effects in attention, memory, anxiety and mental state. Regular chanting of GM shall improve learning power, concentration, prosperity, eternal power, peace and improves quality of life.

\section{Source of Support: Nil}

\section{Conflict of Interest: None Declared}

\section{REFERENCES}

1. Yogitha B, Nagarathna R, John E, Nagendra H. Complimentary effect of yogic sound resonance relaxation technique in patients with common neck pain. Int $\mathrm{J}$ Yoga. 2010;3(1):18-25. doi:10.4103/0973-6131.66774

2. Kalyani BG, Venkatasubramanian G, Arasappa $\mathrm{R}$, et al. Neurohemodynamic correlates of 'OM' chanting: A pilot functional magnetic resonance imaging study. Int $\mathrm{J}$ Yoga. 2011;4(1):3-6. doi:10.4103/0973-6131.78171

3. Karnick CR. Effect of mantras on human beings and plants. Anc Sci Life. 1983;2(3):141-147.

4. Baars BJ. A scientific approach to silent consciousness. Front Psychol. 2013;4:678.

5. Tomasino B, Fregona S, Skrap M and Fabbro F. Meditation-related activations are modulated by the practices needed to obtain it and by the expertise: an ALE meta-analysis study. Front. Hum. Neurosci. 2013;6:346

6. K. A. Manoj Narayanan, N. Venugopalan. Effect of Gayatrimantra chanting on cognitive functions in school children. Int J Pediatr Res. 2018;5(3):113115.

7. Pradhan B, Derle SG. Comparison of effect of Gayatri Mantra and Poem Chanting on Digit Letter Substitution Task. Anc Sci Life. 2012;32(2):8992. 